\title{
Article \\ Development of a Porcine Slaughterhouse Kidney Perfusion Model
}

\author{
Leonie H. Venema * (D) and Henri G. D. Leuvenink
}

Citation: Venema, L.H.; Leuvenink, H.G.D. Development of a Porcine Slaughterhouse Kidney Perfusion Model. Transplantology 2022, 3, 6-19. https: / / doi.org/10.3390/ transplantology3010002

Academic Editors: Derek Manas, Gabriel C. Oniscu, Colin Wilson and Frank Friedersdorff

Received: 21 October 2021

Accepted: 26 December 2021

Published: 28 December 2021

Publisher's Note: MDPI stays neutral with regard to jurisdictional claims in published maps and institutional affiliations.

Copyright: (c) 2021 by the authors. Licensee MDPI, Basel, Switzerland. This article is an open access article distributed under the terms and conditions of the Creative Commons Attribution (CC BY) license (https:// creativecommons.org/licenses/by/ $4.0 /)$.

\author{
Department of Surgery, University Medical Centre Groningen, University of Groningen, \\ 9713 GZ Groningen, The Netherlands; h.g.d.leuvenink@umcg.nl \\ * Correspondence: 1.h.venema@umcg.nl; Tel.: +31-630117620
}

\begin{abstract}
Machine perfusion techniques are becoming standard care in the clinical donation and transplantation setting. However, more research is needed to understand the mechanisms of the protective effects of machine perfusion. For preservation related experiments, porcine kidneys are acceptable alternatives to human kidneys, because of their size and similar physiology. In this experiment, the use of slaughterhouse kidneys was evaluated with normothermic kidney perfusion (NKP), thereby avoiding the use of laboratory animals. Porcine kidneys were derived from two local abattoirs. To induce different degrees of injury, different warm ischemic times and preservation techniques were used. After preservation, kidneys were reperfused for $4 \mathrm{~h}$ with two different NKP solutions to test renal function and damage. The effect of the preservation technique or a short warm ischemic time was clearly seen in functional markers, such as creatinine clearance and fractional sodium excretion levels, as well as in the generic damage marker lactate dehydrogenase (LDH). Porcine slaughterhouse kidneys are a useful alternative to laboratory animals for transplantationand preservation-related research questions. To maintain kidney function during NKP, a short warm ischemic time or hypothermic machine perfusion during the preservation phase are mandatory.
\end{abstract}

Keywords: transplantation; machine perfusion; ischemia reperfusion injury; kidney; DCD

\section{Introduction}

According to the World Health Organization, global organ shortage is a major public health problem, since only $10 \%$ of the worldwide need of organs for transplantation is being met [1]. This organ shortage forces the transplant community to accept organs that are of poor or doubtable quality. Significant attention is also given to improving organ preservation possibilities. One major breakthrough was the introduction of hypothermic machine perfusion as a widely used preservation technique. Machine preservation is usually performed at hypothermic temperatures $\left(<10^{\circ} \mathrm{C}\right)$, following the idea that metabolism is suppressed due to hypothermia. Hypothermic machine perfusion (HMP), as a preservation modality, has already proven to reduce the duration and incidence of delayed graft function (DGF) in deceased donors in comparison with the historical standard preservation technique, static cold storage (SCS) [2]. In addition to the use of MP as a preservation method, it is also used as a platform to assess organ quality by measuring biological functions or as a treatment option. Machine perfusion to test kidney function is conducted at subnormothermic $\left( \pm 21^{\circ} \mathrm{C}\right)$ or normothermic $\left( \pm 37^{\circ} \mathrm{C}\right)$ temperatures, since higher metabolic rates are necessary to assess function $[3,4]$. The feasibility of normothermic machine perfusion (NMP) to test kidney function is currently being investigated in the clinical setting, revealing positive outcomes [5-8].

Although increased use of machine perfusion modalities has been seen over the last decade, in depth research on the mechanisms behind how machine perfusion influences quality is needed-especially since the majority of research to date has focused on clinical applications and the effects on patient and/or graft survival, not on fundamentals of mechanisms. 
For preservation-related experiments, rodent models are less useful, due to their aberrant size and physiology compared to humans. Apart from nonhuman primates, pigs show the closest resemblance to humans and could be used $[9,10]$. However, the laboratory pig model is both expensive and labor intensive. In addition, the use of laboratory animals for research is actively discouraged by several societal organizations and governments. Additionally, in the Netherlands, public acceptance for the use of laboratory animals is declining and regulations are increasing. In 1959, Russell and Burch proposed the principle of the three Rs; Replacement, Reduction and Refinement [11]. This implies the search for replacement for the use of animals for scientific experiments, as well as efforts to minimize the number of animals necessary for experiments, minimize suffering, and increase the wellbeing of the animals used in experiments. In this context, we aimed to develop a relevant model in which machine perfusion-related experiments could be performed without the use of laboratory animals.

Every year, more than 15 million pigs are slaughtered for human consumption in the Netherlands [12]. We considered the kidneys of freshly slaughtered pigs as a potential alternative source for transplantation research. Aside from the ethical considerations of moving from laboratory animals to slaughterhouse material, it is a cost-effective method to acquire materials for scientific research. Laboratory animals need housing, food and medical attention, which is expensive. In this exploratory study, we described which technological and logistic hurdles were considered in the development of the porcine slaughterhouse kidney. Major considerations were: the impact of warm ischemia time, the type of preservation and the type of perfusion solution on kidney function.

\section{Materials and Methods}

\subsection{Animal Model}

Porcine kidneys were obtained from two local abattoirs (Hilbrants/Kroon Vlees, Groningen, The Netherlands) where domestic Dutch landrace pigs (Boar: Tempo $\times$ Sow: Topigs 20) bred for meat consumption were slaughtered at the age of 6 months, at an average weight of $90 \mathrm{~kg}$. Animals were terminated with the standardized procedure of sedative electric shock, followed by exsanguination. For the pigs intended to be used as source for kidneys, approximately $1 \mathrm{~L}$ of blood was collected in a container with $25.000 \mathrm{IU}$ of heparin (LEO Pharma A/S, Ballerup, Denmark). Both kidneys were retrieved and, based on appearance and anatomy, one kidney was chosen for inclusion. No animal ethics committee approval was necessary since slaughterhouse waste material was used.

\subsection{Experimental Design}

Different warm ischemic times (WIT) were applied to have the opportunity to assess different levels of ischemic injury. Three preservation modalities were chosen: static cold storage (CS), non-oxygenated hypothermic machine perfusion $\left(\mathrm{HMP}_{0 \%}\right)$ and oxygenated hypothermic machine perfusion ( $\mathrm{HMP}_{100 \%}$ ). These were chosen to assess different levels of kidney quality as a result of the applied preservation techniques. All kidneys were subsequently reperfused in an ex vivo normothermic kidney perfusion (NKP) setup for a duration of $4 \mathrm{~h}$ using two different NKP strategies (Table 1). The rationale for choosing two different NKP solutions was to see whether renal function would change during normothermic perfusion due to the addition of different nutrients. It is known that amino acids are used in clinical practice to test renal functional reserve [13] and to improve renal function in isolated perfused kidneys [14,15]. Details on the composition of perfusion solutions used are shown in Table 2. 
Table 1. Specification of all kidneys perfused during the development of the slaughterhouse model.

\begin{tabular}{lcccc}
\hline Group, Number of Kidneys & $\begin{array}{c}\text { Warm Ischemic Time } \\
(\mathbf{m i n})\end{array}$ & Preservation & $\begin{array}{c}\text { Mean Duration } \\
\text { Preservation (min) }\end{array}$ & NMP Strategy \\
\hline Group CS S-WIT $(n=2)$ & 7 & $\mathrm{CS}$ & $152 \pm 23$ & Strategy 1 \\
Group CS L-WIT $(n=5)$ & $20-30$ & $\mathrm{CS}$ & $189 \pm 15$ & Strategy 1 \\
Group HMP $_{0 \%}(n=2)$ & 30 & $\mathrm{HMP}_{0}$ & $136 \pm 29$ & Strategy 1 \\
Group HMP $_{100 \%}(n=3)$ & 30 & $\mathrm{HMP}_{100}$ & $175 \pm 7$ & Strategy 1 \\
Group HMP $_{100 \%}+\mathrm{AA}(n=6)$ & $20-30$ & $\mathrm{HMP}_{100 \%}$ & $170 \pm 24$ & Strategy 2 \\
\hline
\end{tabular}

CS, cold storage; S-WIT, short warm ischemic time; L-WIT, long warm ischemic time; HMP, hypothermic machine perfusion; $+\mathrm{AA}$, with addition of amino acids.

Table 2. Perfusion solution characteristics of the two different normothermic perfusion strategies.

\begin{tabular}{|c|c|}
\hline NKP Strategy 1 & NKP Strategy 2 \\
\hline $\begin{array}{l}\text { - } 500 \mathrm{~mL} \text { leukocyte depleted whole blood } \\
\text { - } \quad 300 \mathrm{~mL} \text { lactated ringers (Baxter BV, } \\
\text { Utrecht, The Netherlands) } \\
10 \mathrm{~mL} 8.4 \% \text { sodium bicarbonate (B Braun } \\
\text { Melsungen AG, Melsungen, Germany) } \\
1000 \mathrm{mg} / 200 \mathrm{mg} \\
\text { Amoxicilline/Clavulanic acid (Sandoz BV, } \\
\text { Almere, The Netherlands) } \\
90 \mathrm{mg} \text { creatinine (Sigma-Aldrich, St. } \\
\text { - } \quad 100 \mu \mathrm{HL} 20 \mathrm{mg} / \mathrm{mL} \text { sodium nitroprusside } \\
\text { - } \quad \text { Sigma-Aldrich, St. Louis, MO, USA) } \\
10 \mathrm{~mL} \text { Voluven (Fresenius Kabi, Toronto, } \\
\text { ON, Canada) 5\% Glucose (Baxter BV, } \\
\text { Utrecht, The Netherlands) addition } \\
\text { according to bloodgas analysis. Target } \\
\text { value: } 8 \mathrm{mmol} / \mathrm{L}\end{array}$ & $\begin{array}{l}500 \mathrm{~mL} \text { leukocyte depleted whole blood } \\
300 \mathrm{~mL} \text { lactated ringers } \\
10 \mathrm{~mL} 8.4 \% \text { sodium bicarbonate } \\
1000 \mathrm{mg} / 200 \mathrm{mg} \text { Amoxicilline/Clavulanic acid } \\
90 \mathrm{mg} \text { creatinine } \\
100 \mu \mathrm{L} 20 \mathrm{mg} / \mathrm{mL} \text { sodium } \\
\text { Nitroprusside } \\
6 \mathrm{mg} \text { Mannitol (Sigma-Aldrich, St. Louis, MO, } \\
\text { USA), } \\
6 \mathrm{mg} \text { Dexamethasone (Centrafarm, Etten-Leur, } \\
\text { The Netherlands) } \\
\text { Infusion: } 20 \mathrm{~mL} / \mathrm{h} \\
\text { Total parenteral nutrition (Olimel N7E, Baxter, } \\
\text { Utrecht, The Netherlands) OR 70 mL 10\% } \\
\text { Aminoplasmal (Baxter, Utrecht, The } \\
\text { Netherlands) } \\
100 \text { IU Novorapid (Novo Nordisk, Bagsvaerd, } \\
\text { Denmark) } 24 \text { mL } 8.4 \% \text { sodium bicarbonate }\end{array}$ \\
\hline
\end{tabular}

\subsection{Cold Storage and Hypothermic Machine Perfusion}

After kidney retrieval, the renal artery and ureter were localized and perirenal fat was removed at the slaughterhouse. The kidneys were flushed after a set period of warm ischemia through the renal artery with $0.9 \%$ sodium chloride solution at $4^{\circ}$ Celsius (Baxter $\mathrm{BV}$, Utrecht, The Netherlands) until a clear effluent appeared from the renal vein. In the CS groups, kidneys were stored in an organ preservation bag, submerged in $0.9 \%$ sodium chloride solution at $4^{\circ}$ Celsius (Baxter BV, Utrecht, The Netherlands) and stored on melting ice for several hours.

In the HMP groups the kidneys were cannulated to connect the renal artery to the hypothermic machine perfusion device (Kidney Assist Transport, Organ Assist, Groningen, The Netherlands). The aorta was used to create a patch (Figure 1a), mounted to the patch holder (Figure 1b) and placed in the kidney holder (Figure 1c) in the kidney assist machine (Figure 1d). A total of $330 \mathrm{~mL}$ University of Wisconsin machine perfusion solution (Belzers MP, Bridge to Life Ltd., London, United Kingdom) was used as perfusion solution. Preservation was performed at $4{ }^{\circ} \mathrm{C}$ with pulsatile pressure-controlled perfusion set at a mean arterial pressure of $25 \mathrm{mmHg}(30 / 20 \mathrm{mmHg}$ ). In case of oxygen delivery, $100 \%$ oxygen was supplied to the oxygenator (Hilite LT 1000, Medos Medizintechnik AG, Stolberg, Germany) at a fixed flow rate of $100 \mathrm{~mL} / \mathrm{min}$. Perfusion pressure, flow rate and temperature of the perfusion solution was monitored continuously. After start of the preservation, kidneys were transported to the lab for further experimentation and analysis. 


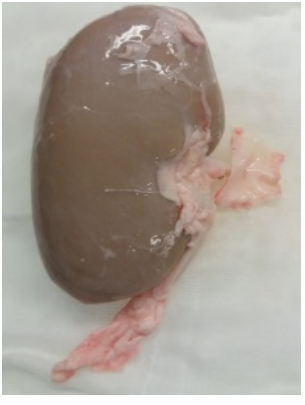

(a)

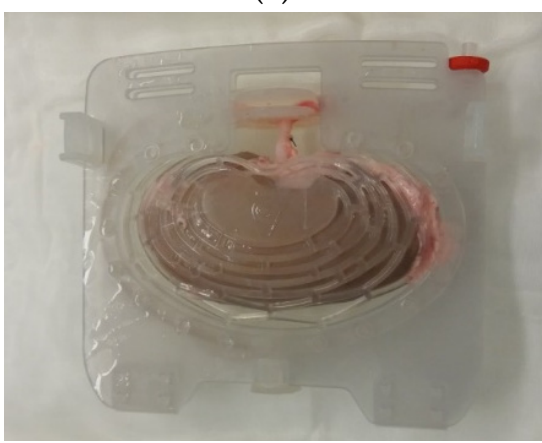

(c)

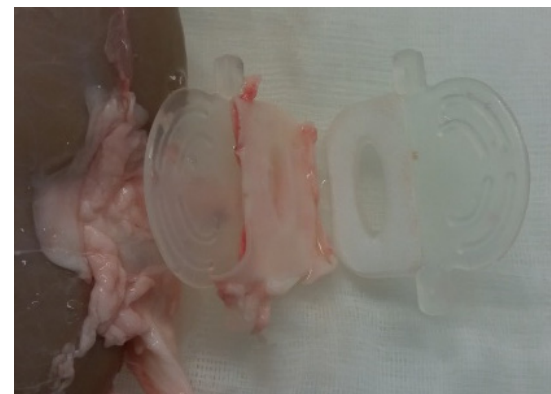

(b)

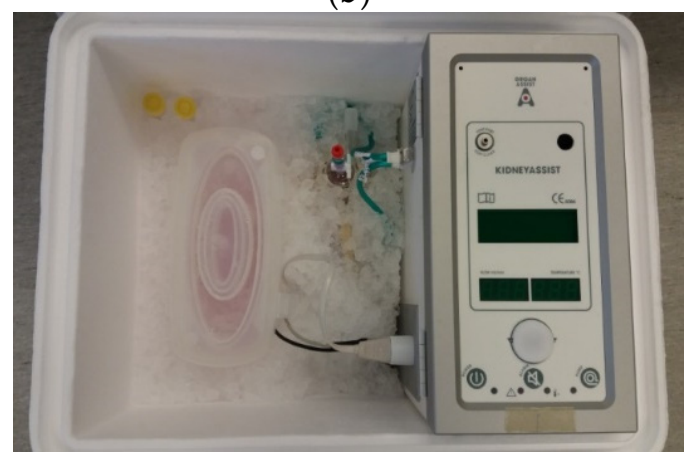

(d)

Figure 1. (a-d) Preparation of the kidneys for hypothermic machine perfusion.

\subsection{Ex Vivo Normothermic Machine Perfusion to Assess Renal Function}

The normothermic perfusion setup consisted of a centrifugal pump motor (Deltastream DP2, Medos Medizintechnik AG, Stolberg, Germany) integrated into the Kidney Assist Transporter (Organ Assist, Groningen, The Netherlands). The software of the pump was adjusted to allow higher perfusion pressures. The disposable perfusion circuit included a centrifugal pump head (Deltastream DP2, Medos Medizintechnik AG, Stolberg, Germany), an oxygenator with integrated heat exchanger (Hilite LT 1000, Medos Medizintechnik AG, Stolberg, Germany), a pressure probe (TrueWave disposable pressure transducer, Edwards Lifesciences, Irvine, CA, USA) and disposable $\frac{1}{4}$ inch tubing (Rehau Rauclai-E, Rehau N.V., Nijkerk, The Netherlands) to connect the separate parts. For flow monitoring, an ultrasonic clamp-on flow probe (ME7PXL clamp $\frac{1}{4}$ inch flow meter, Transonic Systems Inc., Ithaca, NY, USA) was attached. Temperature of the solution was measured with a temperature probe. The kidneys were placed in a specially designed organ chamber during perfusion. The NMP setup was surrounded by an insulated heating cabinet with a feedback system, to maintain the ambient temperature at $37^{\circ} \mathrm{C}$. An overview of the total setup is shown in Figure 2.

The perfusion solution was prepared pre-perfusion, as mentioned in Table 2. First, the collected blood was depleted from leukocytes by means of passing the blood through a leukocyte filter (Bio $\mathrm{R} \mathrm{O}_{2}$ plus, Fresenius Kabi, Zeist, The Netherlands). After this, $500 \mathrm{~mL}$ of the depleted fraction was mixed with $300 \mathrm{~mL}$ Ringers Lactate and supplemented with supporting agents. After both the setup and solution were prepared and equilibrated, the kidney was taken out of the icebox or the hypothermic machine perfusion machine and placed on an ice-cold working station. The renal artery and ureter were cannulated with a 12 and 8 French cannula, respectively. Prior to the start of NKP, the kidney was weighed. NKP was started by placing the kidney in the organ chamber, connected to arterial cannula and perfused for four hours at a mean arterial pressure of $75 \mathrm{mmHg}(90 / 60 \mathrm{mmHg})$ at $37^{\circ}$ Celsius. Throughout the perfusion period, the solution was oxygenated with carbogen, a mixture of $95 \% \mathrm{O}_{2}$ and $5 \% \mathrm{CO}_{2}$, at a fixed flow rate of $0.5 \mathrm{~L} / \mathrm{min}$. 


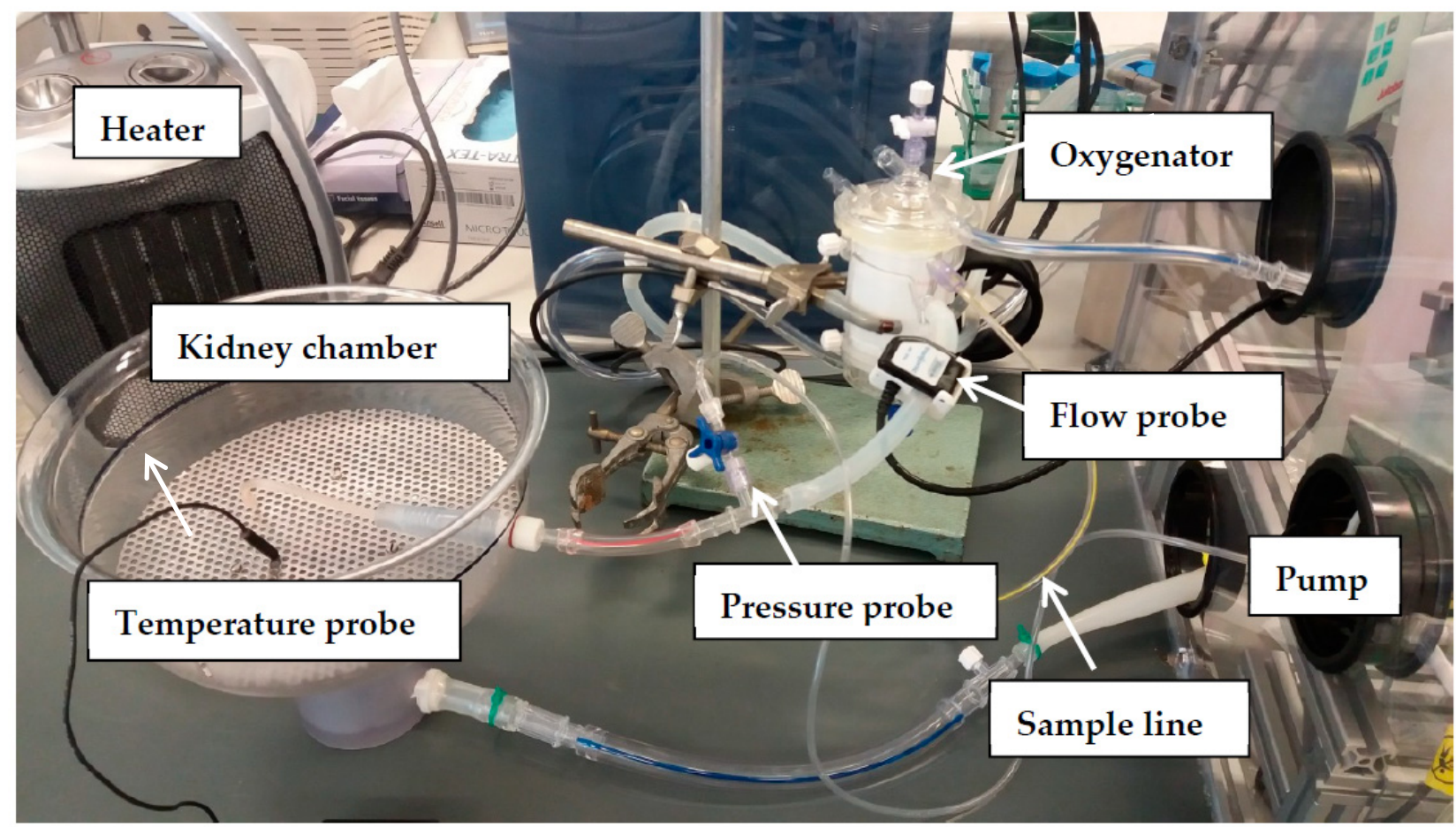

Figure 2. The normothermic perfusion circuit.

\subsection{Evaluation of Renal Function}

The main readout in the development of the model was the assessment of kidney function. Renal flow rates were recorded in ten minute intervals to review the flow pattern. Urine production was measured after 15, 30, 60, 90, 120, 150, 180, 210 and $240 \mathrm{~min}$. Blood and urine samples were collected at these same time points. Furthermore, arterial and venous blood was drawn for blood gas analysis (ABL90 FLEX, Radiometer, Zoetermeer, The Netherlands) to measure partial oxygen pressures, saturation and glucose levels. Concentrations of creatinine and sodium were determined in blood and urine samples by the clinical chemistry lab of the University Medical Center Groningen. With these measurements, creatinine clearance and fractional sodium excretion ( $\mathrm{FeNa}$ ) were calculated with the formulas stated in Table 3. Renal oxygen consumption $\mathrm{QO}_{2}$ was used as an indicator for metabolic activity of the kidneys and was calculated with the formula found in Table 3.

Total sodium reabsorption (TNa) and metabolic coupling of sodium transport by ATPase in tubular epithelial cells were calculated by dividing TNa with renal oxygen $\mathrm{QO}_{2}$ as described in the formula in Table 3.

Enzymatic activities of lactate dehydrogenase (LDH) were determined in the perfusion solution at the clinical chemistry lab according to standard procedures. In short, the international federation of clinical chemistry method was used, meaning that the lactateto-pyruvate conversion was measured at a temperature of $37^{\circ} \mathrm{C}$ at a pH between 8.8-9.8. Plasma was separated by centrifuging the samples for $5 \mathrm{~min}$ at $1800 \times g$ and the samples were subsequently analyzed in the photo spectrometer at $340 \mathrm{~nm}$. 
Table 3. Equations for calculating renal metabolic and functional parameters.

\begin{tabular}{|c|c|c|c|}
\hline Outcome & Unit & Equation & Abbreviations \\
\hline Creatinine clearance & $\begin{array}{l}\mathrm{mL} \min ^{-1} 100 \\
\mathrm{~g}^{-1}\end{array}$ & $\left(\frac{\left(\frac{U_{C r} * U}{P_{C r}}\right)}{g}\right) * 100$ & $\begin{array}{l}U_{C r}, \text { urine creatinine concentration } \\
(\mathrm{mmol} / \mathrm{L}) \text {. } \\
U_{\text {, urine production rate }(\mathrm{mL} / \mathrm{min})} \text {. } \\
P_{\mathrm{Cr}}, \text { perfusate creatinine concentration } \\
(\mathrm{mmol} / \mathrm{L}) \text {. } \\
g, \text { kidney weight (gram). }\end{array}$ \\
\hline $\begin{array}{l}\text { Fractional sodium } \\
\text { excretion }\end{array}$ & $\%$ & $100 * \frac{U_{N a} * P_{C r}}{P_{N a} * U_{C r}}$ & $\begin{array}{l}U_{\mathrm{Na}}, \text { urine sodium concentration }(\mathrm{mmol} / \mathrm{L}) \text {. } \\
P_{\mathrm{Na}}, \text { perfusate sodium concentration } \\
(\mathrm{mmol} / \mathrm{L}) \text {. } \\
P_{\mathrm{Cr}}, \text { perfusate creatinine concentration } \\
(\mathrm{mmol} / \mathrm{L}) \text {. } \\
U_{\mathrm{Cr}}, \text { urine creatinine concentration } \\
(\mathrm{mmol} / \mathrm{L}) \text {. }\end{array}$ \\
\hline $\begin{array}{l}\text { Oxygen } \\
\text { consumption }\left(\mathrm{QO}_{2}\right)\end{array}$ & $\begin{array}{l}\mathrm{mLO}_{2} \min ^{-1} \\
100 \mathrm{~g}^{-1}\end{array}$ & $\begin{array}{l}+\left(p \mathrm{O}_{2} \text { arterial } * \mathrm{~K}\right) \\
-(0.024794 \\
* \mathrm{Hb} * \mathrm{SO}_{2} \text { venous } \\
\left.+\left(p \mathrm{O}_{2} \text { venous } * \mathrm{~K}\right)\right) \\
* Q / \text { Kidney weight } \\
* 100\end{array}$ & $\begin{array}{l}\mathrm{Hb} \text {, hemoglobin content }(\mathrm{mmol} / \mathrm{L}) . \\
\mathrm{pO}_{2} \text {, partial oxygen pressure }(\mathrm{kPa}) . \\
\mathrm{K} \text { solubility constant of oxygen in water at } 37 \\
{ }^{\circ} \mathrm{C}\left(0.0225 \mathrm{mLO}_{2} \text { per } \mathrm{kPa}\right) \text {. } \\
\mathrm{SO}_{2} \text {, hemoglobin saturation }(\%) . \\
\mathrm{Q} \text {, renal blood flow }(\mathrm{L} / \mathrm{min}) . \\
\mathrm{g} \text { kidney weight (gram). }\end{array}$ \\
\hline $\begin{array}{l}\text { Total sodium } \\
\text { reabsorption }\left(\mathrm{T}_{\mathrm{Na}}\right)\end{array}$ & $\begin{array}{l}\mathrm{mmol} \mathrm{min}^{-1} \\
100 \mathrm{~g}^{-1}\end{array}$ & $\left(\frac{\left(C r C l * P_{N a}\right)-\left(U_{N a} * U\right)}{g}\right) * 100$ & $\begin{array}{l}\mathrm{CrCl} \text {, creatinine clearance }(\mathrm{mL} / \mathrm{min}) . \\
P_{\mathrm{Na}}, \text { perfusate sodium concentration } \\
(\mathrm{mmol} / \mathrm{L}) \text {. } \\
U_{\mathrm{Na}} \text {, urine sodium concentration }(\mathrm{mmol} / \mathrm{L}) . \\
U \text {, urine production rate }(\mathrm{mL} / \mathrm{min}) . \\
g, \text { kidney weight (gram). }\end{array}$ \\
\hline $\begin{array}{l}\text { Metabolic coupling } \\
\text { ratio }\end{array}$ & a.u. & $\left(\frac{T N a}{Q O 2}\right)$ & $\begin{array}{l}T_{\mathrm{Na}}, \text { Total sodium reabsorption }\left(\mathrm{mmol} \mathrm{min}^{-1}\right. \\
\left.100 \mathrm{~g}^{-1}\right) \\
\mathrm{QO}_{2}, \text { Oxygen consumption }\left(\mathrm{mLO}_{2} \mathrm{~min}^{-1}\right. \\
100 \mathrm{~g}^{-1}\end{array}$ \\
\hline
\end{tabular}

\subsection{Statistics}

Results were reported as means with standard deviation. All graphs were made with Graphpad Prism 7.02 (San Diego, CA, USA).

\section{Results}

\subsection{Hypothermic and Normothermic Perfusion Parameters}

No differences were seen in HMP flows between the three groups that were HMPpreserved. All groups showed a similar flow pattern, with a steep and fast increase for the first $20 \mathrm{~min}$ and a slowly increasing flow rate thereafter (Figure $3 \mathrm{~A}$ ).

During the four-hour normothermic perfusion, renal blood flow increased in every group in the first hour. The steepness of the slopes and trends were variable between the groups (Figure 3B,C). The highest flow rates were found for the CS S-WIT group, comparable lower flow rates for the CS S-WIT, $\mathrm{HMP}_{100 \%}$ and $\mathrm{HMP}_{100 \%}+\mathrm{AA}$ groups, and the lowest flow rates for the $\mathrm{HMP}_{0 \%}$ group. 

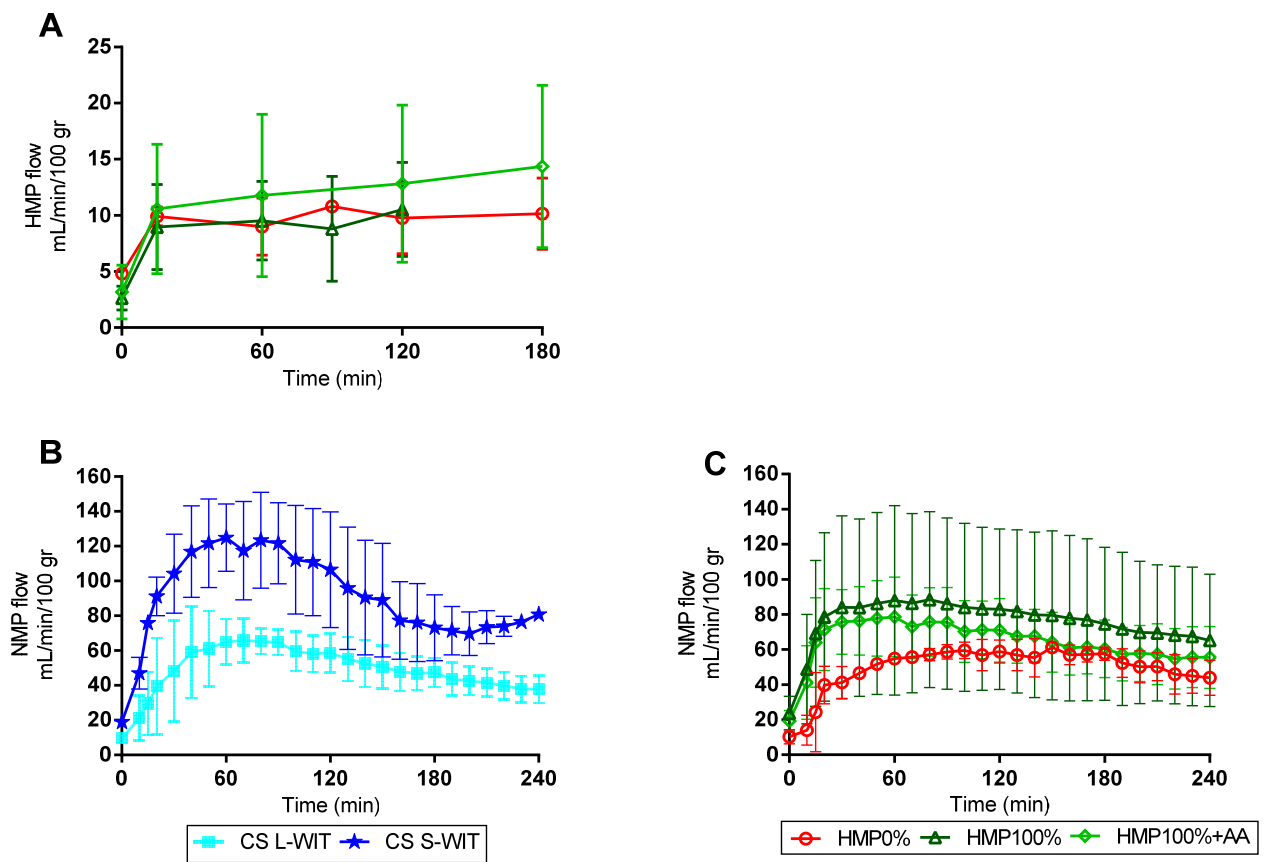

Figure 3. Renal flow rates during hypothermic and normothermic kidney perfusion. Porcine kidneys preserved by CS or HMP for $3 \mathrm{~h}$ and subsequently perfused for $4 \mathrm{~h}$ with a blood-based perfusion solution to test kidney function. (A) Renal flow rates during HMP, (B) Renal flow rates during NKP of CS preserved kidneys. (C) Renal flow rates during NKP of HMP preserved kidneys. CS, cold storage; HMP, hypothermic machine perfusion; NKP, normothermic kidney perfusion. The data are shown as mean $\pm \mathrm{SD}$.

\subsection{Renal Function during Normothermic Perfusion}

Large differences in urine output were seen between the groups. Group CS L-WIT had almost no urine production (total output: $<50 \mathrm{~mL}$ ), while the CS S-WIT kidneys showed a very high output ( $>500 \mathrm{~mL}$ ). (Figure $4 \mathrm{~A}, \mathrm{~B})$ All HMP-preserved kidneys consistently produced urine, with the highest urine production (total output: $>600 \mathrm{~mL}$ ) in the $\mathrm{HMP}_{100 \%}+\mathrm{AA}$ group (Figure $4 \mathrm{E}, \mathrm{F}$ ). In both high urine output groups, a high output during the first $120 \mathrm{~min}$ and a decrease in the last $120 \mathrm{~min}$ was observed.

Creatinine clearance from the circuit was highest in the CS S-WIT and $\mathrm{HMP}_{100 \%}+\mathrm{AA}$ groups, with the highest clearance rate during the first $120 \mathrm{~min}$, followed by a slow decrease. Kidneys in group $\mathrm{HMP}_{0 \%}$ and $\mathrm{HMP}_{100 \%}$ had a stable clearance over time. The kidneys in group CS L-WIT had a very low creatinine clearance rate $(<0.25 \mathrm{~mL} / \mathrm{min} / 100 \mathrm{~g}$ (Figure $4 \mathrm{C}, \mathrm{G}$ ).

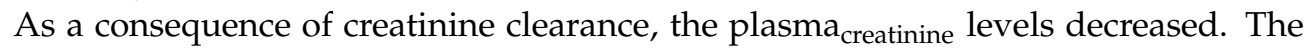
decrease over the total duration of four hours of NKP was comparable for the kidneys in group CS S-WIT $( \pm 650 \mu \mathrm{mol}), \mathrm{HMP}_{100 \%}( \pm 600 \mu \mathrm{mol})$ and $\mathrm{HMP}_{100 \%}+\mathrm{AA}( \pm 650 \mu \mathrm{mol})$. Relative to these groups, the kidneys from group $\mathrm{HMP}_{0} \%$ had a decreased $\Delta$ plasma $( \pm 500 \mu \mathrm{mol})$. The CS L-WIT group has the lowest $\Delta$ plasma $_{\text {creatinine }}(100 \mu \mathrm{mol})$ (Figure $\left.4 \mathrm{D}, \mathrm{H}\right)$. 
A

Cold storage

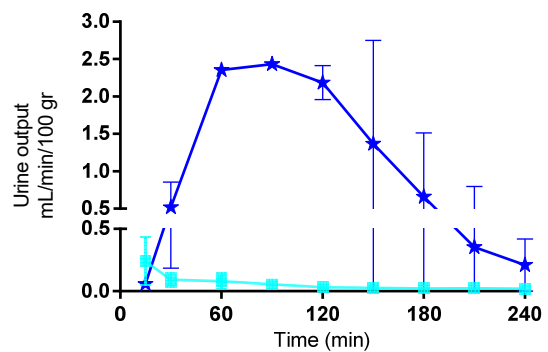

B

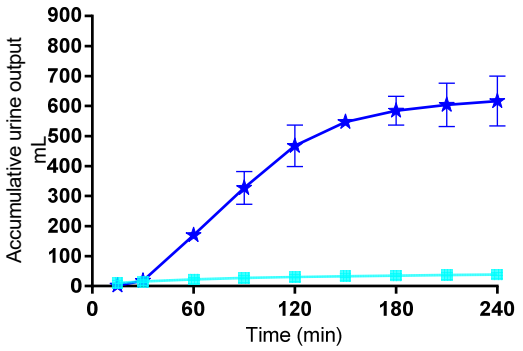

C

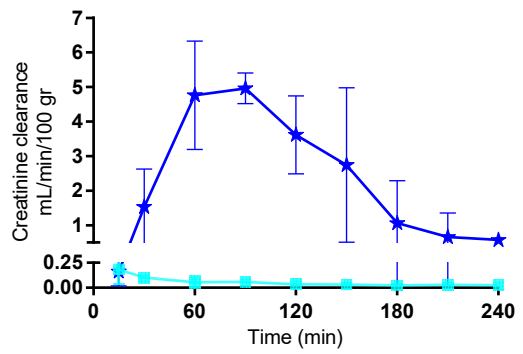

$\mathbf{D}$

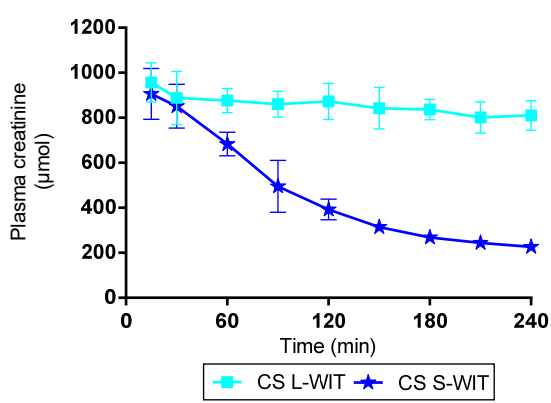

E Hypothermic machine perfusion

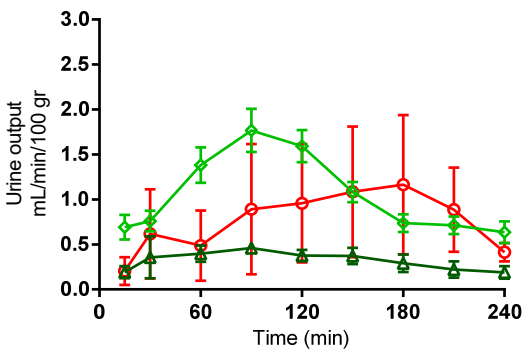

$\mathbf{F}$

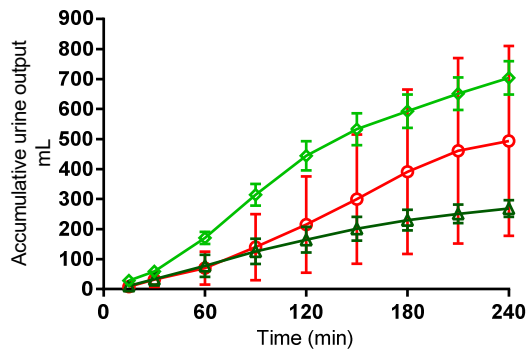

G

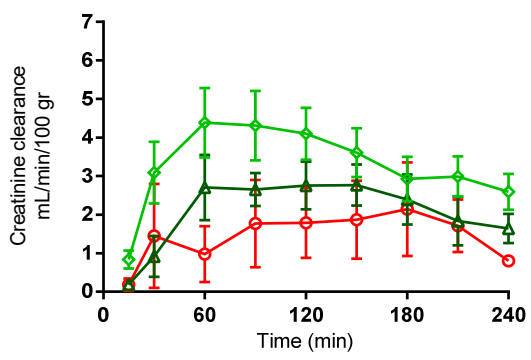

H

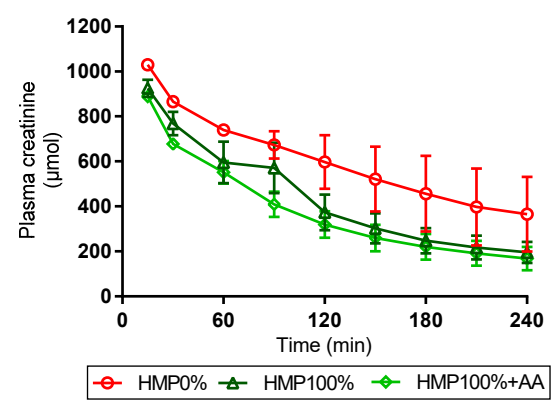

Figure 4. Renal function during normothermic kidney perfusion. Porcine kidneys perfused for $4 \mathrm{~h}$ with a blood-based perfusion solution to test kidney function. (A,E) Urine production during $4 \mathrm{~h}$ NKP for CS and HMP preserved kidneys, $(\mathbf{B}, \mathbf{F})$ accumulative urine production during $4 \mathrm{~h}$ NKP for CS and HMP preserved kidneys, (C,G) creatinine clearance during $4 \mathrm{~h}$ NKP for CS and HMP preserved kidneys, (D,H) serum creatinine levels during $4 \mathrm{~h}$ NKP for CS and HMP preserved kidneys. NKP, normothermic kidney perfusion; CS, cold storage; HMP, hypothermic machine perfusion. The data are shown as mean \pm SD.

\subsection{Metabolic Processes during Normothermic Perfusion}

All kidneys were consuming oxygen during NKP with a slight increase in consumption rates during $4 \mathrm{~h}$ NKP for group CS L-WIT, CS S-WIT, $\mathrm{HMP}_{0 \%}$ and $\mathrm{HMP}_{100 \%}$. Kidneys in 
group $\mathrm{HMP}_{100 \%}+\mathrm{AA}$ used more oxygen during NKP, and a clear difference was obseved between the beginning and end of NKP in terms of oxygen consumption rates (Figure 5A,E).

A Cold storage

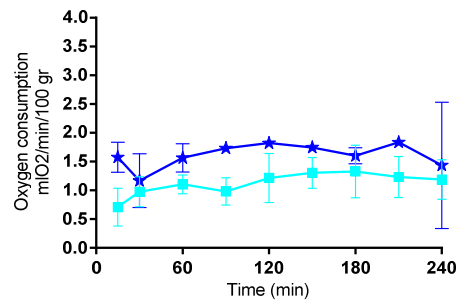

B

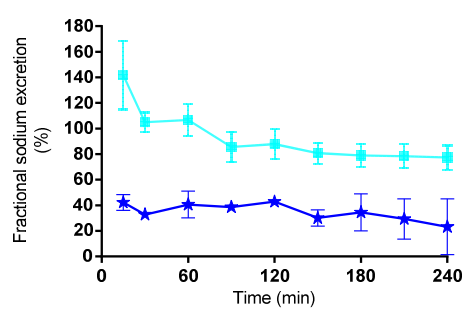

C

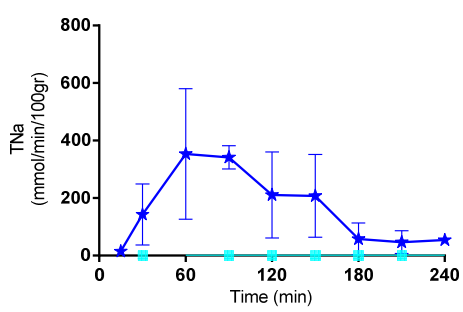

D

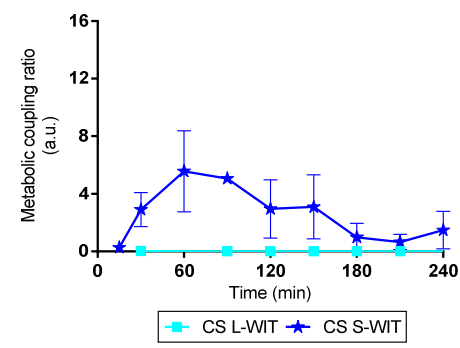

E Hypothermic machine perfusion
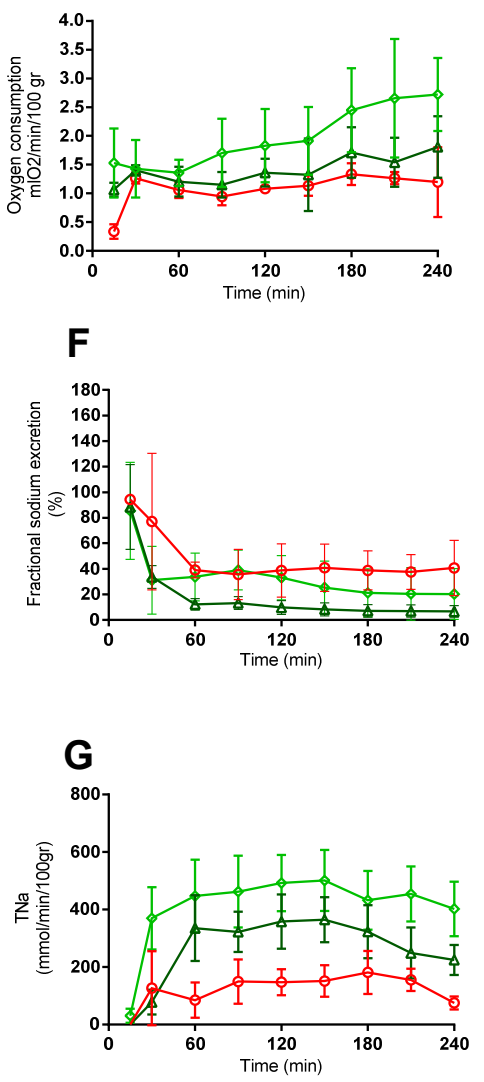

H

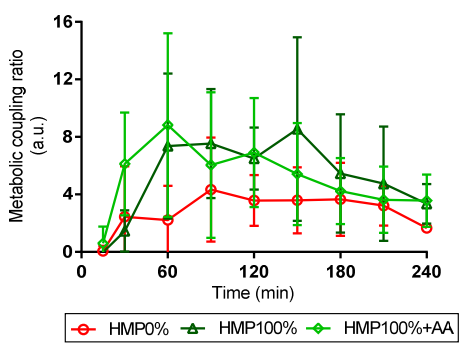

Figure 5. Metabolic processes during normothermic kidney perfusion. Porcine kidneys perfused for $4 \mathrm{~h}$ with a blood-based perfusion solution to test kidney function. (A,E) Oxygen consumption rates during $4 \mathrm{~h}$ NKP for CS and HMP preserved kidneys, (B,F) fractional sodium excretion levels $\left(\mathrm{Fe}_{\mathrm{Na}}\right)$ during $4 \mathrm{~h}$ NKP for CS and HMP preserved kidneys, $(\mathbf{C}, \mathrm{G})$ total sodium reabsorption $\left(\mathrm{T}_{\mathrm{Na}}\right)$ during $4 \mathrm{~h}$ NKP for CS and HMP preserved kidneys, (D,H) metabolic coupling ratio during $4 \mathrm{~h}$ NKP for CS and HMP preserved kidneys. NKP, normothermic kidney perfusion; CS, cold storage; HMP, hypothermic machine perfusion. The data are shown as mean $\pm \mathrm{SD}$.

Fractional sodium excretion rates were high for group CS L-WIT ( $\pm 100 \%)$. All other groups showed improved fractional sodium excretion rates in comparison with this group. All groups, except for CS S-WIT, had a decrease in excretion levels between 15 and $60 \mathrm{~min}$. The kidneys from group CS S-WIT immediately had a fractional sodium excretion rate of approximately 30-40\% (Figure 5B,F). 
Sodium reabsorption rates in the CS L-WIT group were absent and, in line with the fractional sodium excretion rates, all other groups showed improved $\mathrm{T}_{\mathrm{Na}}$ levels in comparison with this group. Kidneys in the $\mathrm{HMP}_{100 \%}+\mathrm{AA}$ group showed the highest sodium reabsorbtion rates.

Metabolic coupling ratios were highest in the two oxygenated HMP groups $\left(\mathrm{HMP}_{100 \%} /\right.$ $\left.\mathrm{HMP}_{100 \%}+\mathrm{AA}\right)$. Lower coupling ratios were found for the $\mathrm{HMP}_{0 \%}$ and CS S-WIT groups and metabolic coupling ratios of approximately 0 were found for the CS L-WIT group (Figure 5D,H).

\subsection{Renal Damage}

The group CS L-WIT showed an increasing LDH concentration during $4 \mathrm{~h}$ of NKP. This resulted in a $\triangle \mathrm{LDH}$ increase for this group that was approximately threefold higher than in all other groups (Figure 6A,D).

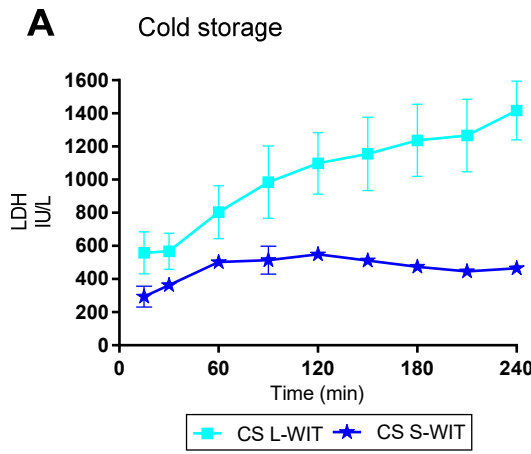

B

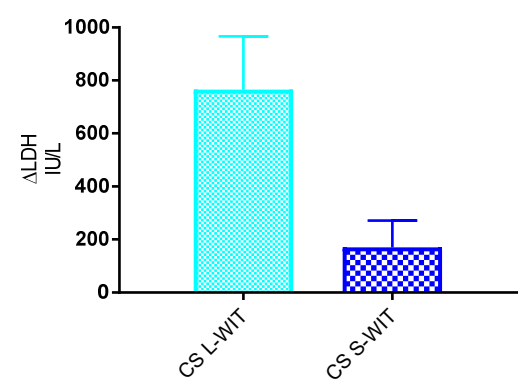

Hypothermic machine perfusion

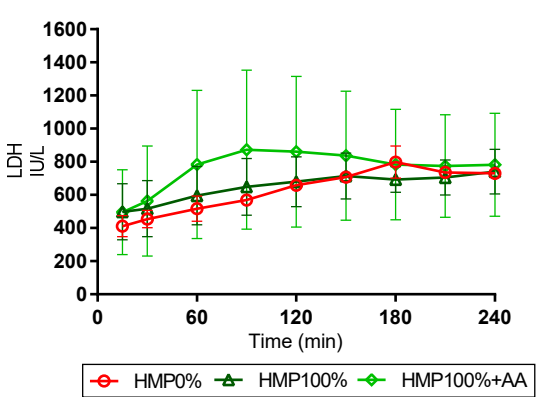

D

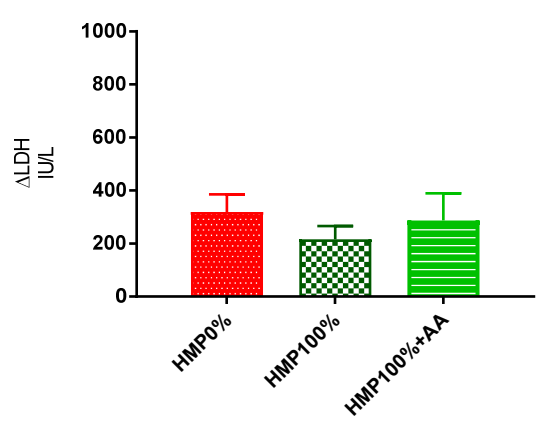

Figure 6. Kidney injury marker. Porcine kidneys perfused for $4 \mathrm{~h}$ with a blood-based perfusion solution to test kidney function. (A,C) LDH release during $4 \mathrm{~h}$ NKP for CS and HMP preserved kidneys, (B,D) delta LDH increase after $4 \mathrm{~h}$ NKP for CS and HMP preserved kidneys. LDH, lactate dehydrogenase; NKP, normothermic kidney perfusion; CS, cold storage; HMP, hypothermic machine perfusion. The data are shown as mean \pm SD.

\section{Discussion}

The aim of these experiments was to find out whether porcine slaughterhouse kidneys were useful as a kidney source for transplantation related purposes, especially for kidney preservation research. For this purpose, it was important that quality differences due to preservation techniques or ischemia duration become visible when testing kidney function during normothermic reperfusion. These differences were clearly seen in functional parameters such as creatinine clearance, as well in tubular functions, represented by fractional sodium excretion and metabolic coupling. In terms of renal damage, we found plasma LDH values that were in line with all other parameters.

Others have attempted to use slaughterhouse organs for transplantation-related research [9,13-20]. Details on the protocols used are given in supplement Table 1. 
The impact of warm ischemia on function was tested in porcine kidneys with a comparable NMP protocol by Hosgood and colleagues [16]. The perfusion solution used by Hosgood was, to a large extent, comparable to our protocol. Therefore, comparisons can be made on functional outcome. Nearly identical results were presented for serum creatinine levels and urine output for kidneys that had a very short warm ischemic time of $7 \mathrm{~min}$. Extended warm ischemic times, however, showed better renal function in the study of Harper, in comparison with our kidneys that were exposed to longer WIT in combination with CS. This could be due to the use of a dedicated hypothermic cold storage solution in contrast to the saline solution used in our experiment. Another study describing the development of a hemoperfused porcine slaughterhouse kidney model showed creatinine clearances 4 times higher than our findings [9]. The use of a simultaneous dialysis module in combination with the perfusion setup resulted in very tight control of electrolytes, metabolites and $\mathrm{pH}$, and could be the explanation for the superior function that they found. However, it also resulted in higher costs and increased complexity of the protocol.

In addition to the impact of warm ischemia, we found that preservation by HMP instead of CS improved renal function. Clinically, it has been established that HMP results in superior early kidney function in donation after cardiac death donor (DCD) kidneys, represented by glomerular filtration rates (GFR) in the period after transplantation [17]. Although the GFR found in healthy individuals is approximately 25 times higher than in our experimental situation [18], the fact that we observed these expected differences in GFR resulting from a superior preservation technique provided confidence in the predictability of this model. In addition, in humans, it is unknown what the exact GFR of a transplanted kidney is during the first hours of reperfusion, which makes a direct comparison with the GFR measurements in our model difficult. This information, however, would be very valuable for a better interpretation of ex vivo kidney perfusion parameters.

In our experiments, we tested two different NKP strategies-with and without the addition of amino acids. The amino acid mixture added during reperfusion contained all 9 essential plus 8 additional amino acids. The choice for these amino acids was based on earlier findings in our lab in which the effect of amino acids on normothermic perfused isolated rat kidneys showed improvements in renal function $[14,15,19,20]$. Although not tested for significance because of the limited number of kidneys in each group, we observed that the addition of this mixture during normothermic reperfusion resulted in improved function and metabolic processes. To our knowledge, this effect has not been described before in porcine kidneys. Further research could be useful to establish which amino acids are resulting in improved renal function and quality during normothermic machine perfusion of pig kidneys.

An important feature of a slaughterhouse model is that it provides an endless source of kidneys without the high costs that are inevitable with (large) laboratory animal research. Furthermore, it has considerable ethical benefits. The use of laboratory animals for scientific purposes is constrained because animal experiments do not always provide necessary information or because better alternatives, with improved predictive values, become available [21,22]. Furthermore, ethical and societal concerns regarding the use and wellbeing of laboratory animals is increasing [23]. The Dutch ministry of agriculture, nature and food quality has announced that The Netherlands hopes to lead the field in the international transition towards laboratory animal-free research, making the development of our model timely and relevant.

However, the slaughterhouse model also has its weaknesses. Due to the procedures and regulations at commercial slaughterhouses that produce meat for human consumption, material (blood, specimens and organs) can only be acquired after the death of the animal. Preexisting injury cannot be assessed because it is not permitted to take any baseline samples prior to death; as such, the exact conditions of the kidneys or blood at start of the experiment can vary. Furthermore, the conditions of an experiment with slaughterhouse organs are less controlled than in a laboratory setting. Many reports describe variability in bacterial load and underlying deceases [24-26]. The work environment is obviously 
different from a laboratory setting, since part of the preparation and retrieval of the kidneys takes place in a food processing plant. A prerequisite for success with such a model is excellent collaboration with all employees to standardize essential issues such as warm ischemic time and handling of organs and blood without undue interference in their work. We invested in this collaboration by inviting them to our laboratory, offering insight into clinical procedures and explaining the importance of the use of standardized protocols. This resulted in a fruitful collaboration that has already lasted for 6 years. This collaboration has involved experiments with kidneys, livers and lungs and has resulted in several scientific papers in high ranked (transplantation) journals [27-34]. Publishing data from slaughterhouse models is hampered by the dogmatic view of many reviewers and editors that transplantation research needs to be conducted in laboratory animal models. We do acknowledge the need for transplantation models since an isolated ex situ organ lacks the neuronal and humoral interaction that is part of the transplantation process. However, many research questions can be answered in the slaughterhouse model before moving on to in vivo experiment in live animals. The timeframe of the model described here was $4 \mathrm{~h}$, which enabled us to assess short-term function and injury. However, longer reperfusion times are possible $[3,35,36]$, although maintaining physiological electrolyte content and $\mathrm{pH}$ is challenging. Perfusion solutions play a pivotal role in supporting organs during ex situ perfusion and improving them will result in the possibility of longer perfusion durations. Fortunately, our model is very suitable for testing of different perfusion solutions.

A limitation of the work described here is that we included too low numbers of kidneys in every group for statistical analysis. Furthermore, we did not collect extra perfusate, urine samples or biopsies. The studies described were our first pilot experiments to see whether it would be possible to preserve and normothermically perfuse porcine kidneys derived from an abattoir. We first focused on basal renal function and injury to finalize protocols that we subsequently used for different research questions that we wanted to address. We have published several papers with the model [28-33].

We have concluded that this model could provide valuable data for kidney preservation and transplantation research. Results obtained indicated that slaughterhouse kidneys could be used to study quality differences in terms of functionality and injury during normothermic perfusion.

Author Contributions: Research design, L.H.V. and H.G.D.L.; performance of experiments, L.H.V.; data analysis, L.H.V.; writing, L.H.V. and H.G.D.L.; supervising, H.G.D.L. All authors have read and agreed to the published version of the manuscript.

Funding: This research received no external funding.

Institutional Review Board Statement: Not applicable.

Informed Consent Statement: Not applicable.

Acknowledgments: We are very grateful for our excellent collaboration with the butchery Dik Hilbrants, Kroon Vlees and the butchery Kuipers and would like to thank them for their support in providing kidneys for this research. Although we felt like we were severely inconveniencing them our machines and the people we brought to their facilities, they have never given us that impression - and even after 4 years of extensive collaboration, we are still welcome. Without them, this would not have been possible.

Conflicts of Interest: The authors declare no conflict of interest.

\section{References}

1. Giwa, S.; Lewis, J.K.; Alvarez, L.; Langer, R.; Roth, A.E.; Church, G.M.; Markmann, J.F.; Sachs, D.H.; Chandraker, A.; Wertheim, J.A.; et al. The promise of organ and tissue preservation to transform medicine. Nat. Biotechnol. 2017, 35, 530-542. [CrossRef]

2. Moers, C.; Smits, J.M.; Maathuis, M.-H.J.; Treckmann, J.; van Gelder, F.; Napieralski, B.P.; Van Kasterop-Kutz, M.; Van Der Heide, J.J.H.; Squifflet, J.-P.; Van Heurn, E.; et al. Machine Perfusion or Cold Storage in Deceased-Donor Kidney Transplantation. N. Engl. J. Med. 2009, 360, 7-19. [CrossRef] [PubMed] 
3. Weissenbacher, A.; Lo Faro, L.; Boubriak, O.; Soares, M.F.; Roberts, I.S.; Hunter, J.P.; Voyce, D.; Mikov, N.; Cook, A.; Ploeg, R.J.; et al. Twenty-four hour normothermic perfusion of discarded human kidneys with urine recirculation. Am. J. Transpl. 2019, 19, 178-192. [CrossRef] [PubMed]

4. Weissenbacher, A.; Hunter, J. Normothermic machine perfusion of the kidney. Curr. Opin. Organ Transplant. 2017, 22, 571-576. [CrossRef]

5. Hosgood, S.A.; Saeb-Parsy, K.; Hamed, M.O.; Nicholson, M.L. Successful Transplantation of Human Kidneys Deemed Untransplantable but Resuscitated by Ex Vivo Normothermic Machine Perfusion. Am. J. Transplant. 2016, 16, 3282-3285. [CrossRef] [PubMed]

6. Hosgood, S.A.; Thompson, E.; Moore, T.; Wilson, C.H.; Nicholson, M.L. Normothermic machine perfusion for the assessment and transplantation of declined human kidneys from donation after circulatory death donors. Br. J. Surg. 2018, 105, 388-394. [CrossRef]

7. Hosgood, S.A.; Saeb-Parsy, K.; Wilson, C.; Callaghan, C.; Collett, D.; Nicholson, M.L. Protocol of a randomised controlled, openlabel trial of ex vivo normothermic perfusion versus static cold storage in donation after circulatory death renal transplantation. BMJ Open. 2017, 7, e012237. [CrossRef]

8. Hosgood, S.A. Renal transplantation after ex vivo normothermic perfusion: The first clinical study. Am. J. Transplant. 2013, 13, 1246-1252.

9. Grosse-Siestrup, C.; Unger, V.; Fehrenberg, C.V.; Baeyer, H.; Fischer, A.; Schäper, F.; Groneberg, D.A. A model of isolated autologously hemoperfused porcine slaughterhouse kidneys. Nephron 2002, 92, 414-421. [CrossRef]

10. William Richard Douglas. Of pigs and men and research: A review of applications and analogies of the pig, sus scrofa, in human medical research. Space Life Sci. 1972, 3, 226-234.

11. Russell WMS, B.K. The Principles of Humane Experimental Technique; UFAW: London, UK, 1959.

12. CBS Statline. Available online: https://opendata.cbs.nl/statline/\#/CBS/nl/dataset/7123slac/table?fromstatweb (accessed on 28 December 2021).

13. Gabbai, F.B. The role of renal response to amino acid infusion and oral protein load in normal kidneys and kidney with acute and chronic disease. Curr. Opin. Nephrol. Hypertens. 2018, 27, 23-29. [CrossRef]

14. Brezis, M.; Silva, P.; Epstein, F.H. Amino acids induce renal vasodilatation in isolated perfused kidney: Coupling to oxidative metabolism. Am. J. Physiol. Hear Circ. Physiol. 1984, 247, H999-H1004. [CrossRef]

15. Epstein, F.H.; Brosnan, J.T.; Tange, J.D.; Ross, B.D. Improved function with amino acids in the isolated perfused kidney. Am. J. Physiol. Ren. Fluid Electrolyte Physiol. 1982, 243, F284-F292. [CrossRef]

16. Harper, S.J.F.; Hosgood, S.A.; Waller, H.L.; Yang, B.; Kay, M.D.; Goncalves, I.; Nicholson, M.L. The effect of warm ischemic time on renal function and injury in the isolated hemoperfused kidney. Transplantation 2008, 86, 445-451. [CrossRef] [PubMed]

17. Jochmans, I.; Moers, C.; Smits, J.M.; Leuvenink, H.G.; Treckmann, J.; Paul, A.; Rahmel, A.; Squifflet, J.P.; van Heurn, E.; Monbaliu, D.; et al. Machine perfusion versus cold storage for the preservation of kidneys donated after cardiac death: A multicenter, randomized, controlled trial. Ann Surg. 2010, 252, 756-762. [CrossRef] [PubMed]

18. Denic, A.; Mathew, J.; Lerman, L.O.; Lieske, J.C.; Larson, J.J.; Alexander, M.P.; Rahmel, A.; Squifflet, J.P.; van Heurn, E.; Monbaliu, D.; et al. Single-Nephron Glomerular Filtration Rate in Healthy Adults. N. Engl. J. Med. 2017, 376, 2349-2357. [CrossRef]

19. El Sayed, A.A.; Haylor, J.; El Nahas, A.M. Differential effects of amino acids on the isolated perfused rat kidney. Clin. Sci. 1990, 79, 381-386. [CrossRef]

20. El Sayed, A.A.; Haylor, J.; El Nahas, A.M. Mediators of the direct effects of amino acids on the rat kidney. Clin. Sci. 1991, 81, 427-432. [CrossRef] [PubMed]

21. Raad voor Volksgezondheid en Samenleving. Development of New Medicines. Better, Faster, Cheaper; Raad voor Volksgezondheid en Samenleving: Utrecht, The Netherlands, 2017.

22. Freires, I.A.; de Sardi, J.C.O.; de Castro, R.D.; Rosalen, P.L. Alternative Animal and Non-Animal Models for Drug Discovery and Development: Bonus or Burden? Pharm. Res. 2017, 34, 681-686. [CrossRef] [PubMed]

23. Development of New Medicines-Better, Faster, Cheaper; Voortgangsrapport-Dierproeven; Kamerstuk 32336, nr. 112 I Overheid.nl; Officiële bekendmakingen: Utrecht, The Netherlands, 2017; Volume 32336.

24. Hopman, N.E.M.; Oorburg, D.; Sanders, I.; Kuijper, E.J.; Lipman, L.J.A. High occurrence of various clostridium difficile PCR ribotypes in pigs arriving at the slaughterhouse. Vet. Q. 2011, 31, 179-181. [CrossRef]

25. Swanenburg, M.; Gonzales, J.L.; Bouwknegt, M.; Boender, G.J.; Oorburg, D.; Heres, L.; Wisselink, H.J. Large-scale serological screening of slaughter pigs for Toxoplasma gondii infections in The Netherlands during five years (2012-2016): Trends in seroprevalence over years, seasons, regions and farming systems. Vet. Parasitol. X 2019, 276, 100017. [CrossRef] [PubMed]

26. Hulsegge, B.; de Greef, K.H.; Hulsegge, I. A time-series approach for clustering farms based on slaughterhouse health aberration data. Prev. Vet. Med. 2018, 153, 64-70. [CrossRef] [PubMed]

27. Pool, M.; Eertman, T.; Sierra Parraga, J.; t Hart, N.; Roemeling-van Rhijn, M.; Eijken, M.; Jespersen, B.; Reinders, M.; Hoogduijn M.; Ploeg, R.; et al. Infusing Mesenchymal Stromal Cells into Porcine Kidneys during Normothermic Machine Perfusion: Intact MSCs Can Be Traced and Localised to Glomeruli. Int. J. Mol. Sci. 2019, 20, 3607. [CrossRef] [PubMed]

28. Hendriks, K.D.; Brüggenwirth, I.M.; Maassen, H.; Gerding, A.; Bakker, B.; Porte, R.J.; Henning, R.H.; Leuvenink, H.G. Renal temperature reduction progressively favors mitochondrial ROS production over respiration in hypothermic kidney preservation. J. Transl. Med. 2019, 17, 265. [CrossRef] 
29. Venema, L.H.; Brat, A.; Moers, C.; 't Hart, N.A.; Ploeg, R.J.; Hannaert, P.; Minor, T.; Leuvenink, H.G. Effects of oxygen during long-term hypothermic machine perfusion in a porcine model of kidney donation after circulatory death. Transplantation. 2019, 103, 2057-2064. [CrossRef]

30. Maassen, H.; Hendriks, K.D.W.; Venema, L.H.; Henning, R.H.; Hofker, S.H.; van Goor, H.; Leuvenink, H.G.D.; Coester, A.M. Hydrogen sulphide-induced hypometabolism in human-sized porcine kidneys. PLoS ONE. 2019, 14, e0225152. [CrossRef]

31. Huijink, T.M.; Venema, L.H.; Posma, R.A.; de Vries, N.J.; Westerkamp, A.C.; Ottens, P.J.; Touw, D.J.; Nijsten, M.W.; Leuvenink, H.G. Metformin Preconditioning and Postconditioning to Reduce Ischemia Reperfusion Injury in an Isolated Ex Vivo Rat and Porcine Kidney Normothermic Machine Perfusion Model. Clin. Transl. Sci. 2020, 14, 222-230. [CrossRef]

32. Posma, R.A.; Venema, L.H.; Huijink, T.M.; Westerkamp, A.C.; Mireille AWessels, A.; de Vries, N.J.; Doesburg, F.; Roggeveld, J.; Ottens, P.J.; Touw, D.J.; et al. Increasing metformin concentrations and its excretion in both rat and porcine ex vivo normothermic kidney perfusion model. BMJ Open Diabetes Res. Care. 2020, 8, e000816. [CrossRef]

33. Venema, L.H.; van Leeuwen, L.L.; Posma, R.A.; van Goor, H.; Ploeg, R.J.; Hannaert, P.; Hauet, T.; Minor, T.; Leuvenink, H.G. Impact of Red Blood Cells on Function and Metabolism of Porcine Deceased Donor Kidneys During Normothermic Machine Perfusion. Transplantation 2021. Publish Ahead of Print: 1-30. [CrossRef]

34. Brüggenwirth, I.M.A.; van Leeuwen, O.B.; de Vries, Y.; Bodewes, S.B.; Adelmeijer, J.; Wiersema-Buist, J.; Lisman, T.; Martins, P.N.; de Meijer, V.E.; Porte, R.J. Extended hypothermic oxygenated machine perfusion enables ex situ preservation of porcine livers for up to 24 hours. JHEP Reports 2020, 2, 100092. [CrossRef]

35. Kaths, J.M.; Echeverri, J.; Linares, I.; Cen, J.Y.; Ganesh, S.; Hamar, M.; Urbanellis, P.; Yip, P.; John, R.; Bagli, D.; et al. Normothermic Ex Vivo Kidney Perfusion Following Static Cold Storage-Brief, Intermediate, or Prolonged Perfusion for Optimal Renal Graft Reconditioning? Am. J. Transplant. 2017, 17, 2580-2590. [CrossRef] [PubMed]

36. Kaths, J.M.; Cen, J.Y.; Chun, Y.M.; Echeverri, J.; Linares, I.; Ganesh, S.; Yip, P.; John, R.; Bagli, D.; Mucsi, I.; et al. Continuous Normothermic Ex Vivo Kidney Perfusion Is Superior to Brief Normothermic Perfusion Following Static Cold Storage in Donation After Circulatory Death Pig Kidney Transplantation. Am. J. Transplant. 2017, 17, 957-969. [CrossRef] [PubMed] 